\title{
Is the family physician an accomplice in the development of the 'primary care gap'? The importance of high quality real-life primary care respiratory research
}

\author{
*Anthony D'Urzo ${ }^{1,2}$ \\ 1 Associate Professor, Department of Family and Community \\ Medicine, University of Toronto, Canada \\ 2 Chair, Primary Care Respiratory Alliance of Canada (PCRC) \\ *Correspondence: Associate Professor Anthony D'Urzo, \\ Department of Family and Community Medicine, Faculty of \\ Medicine, University of Toronto, 500 University Ave, 5th Floor, \\ Toronto, Ontario M5G 1V7, Canada \\ Tel: 416-652-9336 Fax: 416-652-0218 \\ E-mail: tonydurzo@sympatico.ca
}

With the management of complex chronic care shifting from the hospital to the community clinic setting, identifying and bridging important gaps in the provision of care for patients will be a central responsibility of the primary care provider. In Canada, organisations that fund healthcare delivery have already begun a formal review of current practice patterns in family medicine in order to understand more fully how patient care and healthcare costs can be optimised. ${ }^{1}$ To a large extent, this process will be driven by a mandate to assess the contribution of family physicians to persistent care gaps that threaten to overwhelm public health services and resources.

A 'care gap' represents a difference in health outcomes between best care and usual care. ${ }^{2}$ Recent Canadian data show that family physicians are major drivers of drug prescriptions, diagnostic testing, and the healthcare system as a whole. ${ }^{1}$ In fact, drug costs represent the second-highest spend in the Canadian healthcare system. ${ }^{3}$ Some might argue that this information provides a legitimate basis for considering the family physician (at least in part) as a leading accomplice in the development of care gaps related to pharmacotherapy utilisation. For example, despite the availability of new treatments for asthma, and evidence-based Canadian asthma guidelines that are regularly updated, ${ }^{4-6}$ asthma control in Canada remains suboptimal.?

What might be the reasons for this? A recent study suggests that a median of only $6 \%$ (range $0 \%-43 \%$ ) of patients treated for asthma meet the eligibility criteria for major trials cited in evidencebased treatment guidelines. ${ }^{8}$ In his excellent article published in the $P C R J$ in 2010, ${ }^{9}$ Halpin outlines many fundamental limitations of landmark COPD trials and how such trial data may be difficult to apply at the primary care level. For example, in relation to trials such as
ISOLDE, ${ }^{10,11}$ TORCH $^{12}$ and UPLIFT, ${ }^{13}$ there has been minimal, if any, discussion around the pragmatic implications of high early withdrawal rates from the active treatment arms in these studies - a reality that invariably compounds the difficulty of translating trial information into the most cost-effective care for our primary care patients. Since numbers-needed-to-treat are difficult to adjust for early terminators, it is likely that treatment effects are often overstated in these landmark trials, thus further contributing to perceived care gaps in the real world.

In the UK, most patient contact and $90 \%$ of prescribing occur in primary care - yet until recently much of the evidence to support this activity was generated in secondary or tertiary care settings. ${ }^{14}$ Similar trends are observed in Canada. ${ }^{1}$ There are also reports which suggest that most primary care clinically-relevant research uses less rigorous study designs - such as the cross-sectional survey - and that the majority of papers do not meet established criteria for relevance and validity. ${ }^{15}$ This potential disconnect between family medicine's limited involvement in pharmacotherapeutic research and its role in driving drug costs represents a leadership void that could leave our discipline incapable of effectively identifying and bridging care gaps in a timely manner. This scenario likely also applies to other areas of healthcare delivery that are driven by family physician activities.

Outside the pharmacotherapeutic domain, it is sobering to consider that some clinical guideline recommendations cannot be translated into clinical practice in their current form yet continue to be widely promoted in primary care with little effort directed at conducting formal validation studies. For example, many guidelines recommend simple (pre- and post-bronchodilator) spirometry as the first line test for asthma diagnosis in primary care. In the Canadian asthma management guideline $e^{4}$ this strategy is rated as level 4 evidence - a rating that acknowledges the lack of randomised trials on the subject. What is not outlined in guideline recommendations is the very low sensitivity of spirometry (compared to methacholine challenge testing) for confirming a diagnosis of asthma at the time of testing. ${ }^{16}$ In fact, fewer than $20 \%$ of patients with a physician diagnosis of asthma will respond to a bronchodilator challenge in accordance with guideline-defined spirometric diagnosis of asthma. ${ }^{16-19}$ Most patients with asthma managed in primary care have lung function that is well preserved and which changes little in response to a bronchodilator challenge. ${ }^{20}$ This begs the question; why utilise a firstline diagnostic test that will be helpful, at best two out of ten times, when other more sensitive tests like methacholine challenge testing 
can be made available to most primary care physicians in a reasonably timely fashion? Furthermore, what are physicians to do with patients who have suspected asthma and who have normal lung function on initial testing? Treating such patients on clinical grounds risks overdiagnosis and renders future spirometry testing almost irrelevant. To date, there are no data describing the cost implications of diagnosing asthma in primary care using simple spirometry compared to methacholine challenge. These comments are not meant as a slight against simple spirometry - with its well-established role in evaluating pulmonary mechanics - but a recognition that more convincing, pragmatic evidence is required before costly, widespread adoption of spirometry as the key test for diagnosing asthma is considered standard practice in primary care.

It is likely therefore, that the family physician is an unknowing accomplice in the development of primary care gaps, since guidelines developed in the tertiary setting are used to drive care in the primary care environment. Furthermore, given that family medicine is a major driver of drug costs, is it fair to suggest that family physicians have a professional obligation to participate in pharmaceutical-sponsored clinical trials in order to create opportunities to participate directly in guideline development? ${ }^{21}$ is it also fair to suggest that if family physicians are not developing clinical guidelines and messages firsthand they simply become messengers for those who are?

The great challenge faced by family medicine is the translation of knowledge, often acquired in a very controlled setting, into a clinical practice environment (i.e. primary care) that is as much diverse as it is complex. Simply attempting to implement published guidelines relating to common chronic conditions like asthma and COPD may fall well short of delivering the best care. Simply being critical of the available scientific literature may not allow for more appropriate generalisations that might serve to bridge care gaps. For example, while many study designs may appear appropriate, the questions being addressed may not deal with issues that have meaningful primary care relevance.

Nevertheless, we must not forget the rapid progress that our discipline has made in recent years. The publication of the International Primary Care Respiratory Group guidelines in this journal in $2006^{22}$ represented a pivotal leadership milestone that will provide us with much needed direction for years to come. Outstanding primary care research such as that by Price et al. ${ }^{23}$ which examined the benefits of leukotriene modifying agents in asthma care, brilliantly clarifies the disconnect between real world research studies and findings reported in traditional trials that are more rigidly controlled. The $P C R J$ itself is a fundamental part of this progress, with the publication of top quality primary care-relevant research - as epitomised by the excellent research papers in this issue - and recent initiatives such as the education@pcrj section which enhance our ability to translate knowledge into effective day-to-day patient management.

This progress must continue. Evolving fiscal realities in Canada and other parts of the world will dictate an increasing role for family physicians to be wise stewards of scarce resources. Without a paradigm shift in how evidence is acquired and adopted into the primary care setting, family physicians will invariably be forced to accept the role of accomplice in the development of primary care gaps.

Acknowledgements | would like to thank all my colleagues who encouraged me to be constructively critical about our role in knowledge acquisition with a view to carving new leadership strategies that may serve to promote better patient care that is cost effective.

Conflicts of interest The author declares that he has no conflicts of interest in relation to this article. He is an Associate Editor of the PCRJ, but was not involved in the editorial review of, nor the decision to publish, this article.

Commissioned article; not externally peer-reviewed; accepted 27th December 2012; online 29th January 2013

(c) 2013 Primary Care Respiratory Society UK. All rights reserved http://dx.doi.org/10.4104/pcrj.2013.00006 Prim Care Respir J 2013; 22(1): 1-3

\section{References}

1. Health Council of Canada: Decision, Decisions. September 2010

2. Montague T. Patients First: Closing the Health Care Gap in Canada John Willy and Sons Inc. 2004

3. Health Council of Canada. Progress report 2011. Health care renewal in Canada. Toronto, ON: Health Council of Canada; 2011. Available from: http://healthcouncilcanada.ca/tree/2.45-2011Progress_ENG.pdf Accessed 2012 December 09.

4. Boulet LP, Becker A, Berube D, Beveridge R, Ernst P. Canadian Asthma Consensus Group. Canadian Asthma Consensus Report, 1999. CMAJ 1999;161(Suppl 11):S1S61.

5. Boulet L-P, Bai TR, Becker A, et al. What is new since the last (1999) Canadian Asthma Consensus Guidelines? Can Respir J 2001;8(Suppl A):3A-27A.

6. Lemiere C, Bai T, Balter M, et al. Adult Asthma Consensus Guidelines Update 2003. Can Respir J 2003;11(Suppl A):9A-18A).

7. Chapman KR, Ernst P, Grenville A, Dewland P, Zimmerman S. Control of asthma in Canada: Failure to achieve guideline targets. Can Respir J 2001;8(Suppl A):35A40A).

8. Travers J, Marsh S, Williams M, et al. External validity of randomized controlled trials in asthma: to whom do the results of the trials apply? Thorax 2007;62:219-23. http://dx.doi.org/10.1136/thx.2006.066837

9. Halpin DMG, Lessons from the major studies in COPD: problems and pitfalls in translating research evidence into practice. Prim Care Respir J 2010;19(2):170-9. http://dx.doi.org/10.4104/pcrj.2010.00015

10. Calverley PMA, Spencer S, Willis L, et al., on behalf of the ISOLDE study group. Withdrawal from treatment as an outcome in the ISOLDE study. Chest 2003; 124:1350-1356. http://dx.doi.org/10.1378/chest.124.4.1350

11. D'Urzo AD. Withdrawal of treatment in the ISOLDE study. Chest 2004;125(6):2368 http://dx.doi.org/10.1378/chest.125.6.2368

12. Calverley PM, Anderson JA, Celli B, et al. Salmeterol and fluticasone propionate and survival in chronic obstructive pulmonary disease. $N$ Engl J Med 2007;356(8):775-89. http://dx.doi.org/10.1056/NEJMoa063070

13. Tashkin DP, Celli B, Senn S, et al. A 4-year trial of tiotropium in chronic obstructive pulmonary disease. $N$ Engl J Med 2008;359(15):1543-54. http://dx.doi.org/10.1056/NEJMoa0805800

14. Mant D. National Working Group on R\&D in Primary Care: Final Report. Bristol: NHS Executive South and West, 1997].

15. Merenstein J, Rao G, D'Amico F. Clinical Research in Family Medicine: Quantity and Quality of Published Articles. Fam Med 2003;35(4):284-8.

16. Aaron SD, Vandemheen $\mathrm{KL}$, Boulet $\mathrm{LP}$, et al. Overdiagnosis of asthma in obese and non-obese adults. CMAJ 2008;179(11):1121-31. http://dx.doi.org/10.1503/ cmaj.081332

17. D'Urzo AD. Spirometry in primary care practices. CMAJ 2009;180(4):429-30. http://dx.doi.org/10.1503/cmaj.1080129

18. D'Urzo AD. Must family physicians use spirometry in managing asthma patients? 
NO. Can Fam Physician 2010;56(2):127, 129, 131, 133; discussion e50, e52

19. Luks VP, Vandemheen KL, Aaron SD. Confirmation of asthma in an era of over diagnosis. Eur Respir J 2010;36:255-60. http://dx.doi.org/10.1183/ 09031936.00165109

20. Lusuardi M, De Benedetto F, Paggiaro P, et al. A randomized controlled trial on office spirometry in asthma and COPD in standard general practice: data from spirometry in asthma and COPD: a comparative evaluation Italian study. Chest 2006;129(4):844-52. http://dx.doi.org/10.1378/chest.129.4.844

21. D'Urzo AD. Does family medicine have a professional obligation to play a leading role in pharmaceutical industry-sponsored drug research?: yes. Can Fam Physician 2011;57(8):870, 872, 874, 876; discussion e277, e279.

22. van Schayck CPO, Levy ML, Stephenson P, Sheikh A. The International Primary Care Respiratory Group (IPCRG) Guidelines for the Management of Chronic Respiratory Diseases in Primary Care. Prim Care Respir J 2006;15(1):1-4.

23. Price D, Musgrave SD, Shepstone L, et al. Leukotriene Antagonists as First-Line or Add-on Asthma-Controller Therapy. N Engl J Med 2011;364:1695-707. http://dx.doi.org/10.1056/NEJMoa1010846

\section{The role of primary care as part of the multidisciplinary team (MDT) in the management of lung cancer: the "Dream MDT" report - new guidance from the UK Lung Cancer Coalition}

\section{*David Bellamy', Mick Peake², Andrea Williams ${ }^{3}$}

1 Retired general practitioner; member of the UK Lung Cancer Coalition

2 Consultant and Senior Lecturer in Respiratory Medicine, University Hospitals of Leicester, Leicester, UK; Clinical Lead for the UK National Cancer Intelligence Network (NCIN) and the UK National Lung Cancer Audit Programme (NLCA); Chairman, clinical section of the UK Lung Cancer Coalition

3 General practitioner, King Street Surgery, Hereford, UK; GP adviser for Herefordshire Clinical Commissioning Group; GP spokesperson for the UK Lung Cancer Coalition

*Correspondence: Dr David Bellamy, 8 Littledown Drive, Bournemouth, BH7 7AQ

Tel: +44 (0)1202 394443 E-mail: david.bellamy@virgin.net

Lung cancer is one of the commonest cancers in the UK, with 39,000 new cases diagnosed each year -1 in 7 of all cancers. It causes 35,000 deaths annually, ${ }^{1}$ more than breast and prostate cancer combined. Globally, large increases will occur in developing countries such as China due to increased smoking prevalence. Traditionally men have been more frequently affected than women; however, in the last five years a decline in incidence in males has been observed, whereas incidence rates in women are increasing so that lung cancer has now overtaken breast cancer as a cause of death in women.

Overall, lung cancer has a very poor prognosis which sadly has improved relatively little in the last 40 years. Only $21 \%$ of patients are alive after one year and at five years a mere $9 \%$ are still surviving. ${ }^{2}$ Survival in the UK is three percentage points lower than the European average and seven to 10 points lower than the USA. It has been estimated that 3,500 lives could be saved each year if UK survival rates were improved to be the best in Europe. ${ }^{3}$ Recent research has shown that $39 \%$ of lung cancer patients first present as an emergency admission to hospital and that these patients have a significantly worse prognosis. ${ }^{4}$

There is also evidence of wide variation in the management and outcomes of patients with lung cancer within the UK itself. ${ }^{5}$ The UK
National Lung Cancer Audit has shown that the proportion of patients undergoing surgical treatment varies by a factor of about four between various hospital multi-disciplinary teams (MDTs) throughout the UK, and that most of this variation is not explained by case mix variables.

Studies looking for explanations as to why UK survival figures for lung cancer are so poor have identified a number of contributory causes. One of the main problems is that the vast majority of patients do not present to specialist care until their disease has advanced to a stage when it is essentially incurable. One study comparing excess deaths between England, Norway and Sweden, demonstrated that England had a higher proportion of excess deaths at five years in all age groups but that the large percentage of these excess deaths could be explained by deaths within three months of diagnosis. ${ }^{6}$ Since there are no screening programmes in any of the three countries, the implication has to be that patients with symptomatic lung cancer are getting treatment earlier in Scandinavia. The public are poorly informed about lung cancer symptoms ${ }^{7}$ and seem to have little idea of the scale of risk of lung cancer from smoking. In a recent Scottish study, the median time from the earliest reported symptom to consultation was 99 days $^{8}$ and a questionnaire revealed that $75 \%$ of participants had unrecognised symptoms of lung cancer. The presence of COPD, which increases the risk of lung cancer up to five times, ${ }^{9}$ often delays diagnosis. Estimates suggest that the causes for delay between first symptom and presentation to specialist care can be split equally between patient-related and primary care-related issues. ${ }^{10}$

In order to increase public awareness about lung cancer, the UK Department of Health funded a pilot, high profile media campaign in the Midlands region of England for a 5-week period in October and November 2011. This used the brand 'Be Clear on Cancer', and encouraged people over 50 with a persistent cough, the commonest symptom of lung cancer, to seek advice from their general practitioner (GP). A national campaign followed in the summer of 2012 and the results of these initiatives are awaited with interest.

In a further attempt to address these problems, a team of lung cancer experts from primary and secondary care, representing the UK Lung Cancer Coalition, has just published a new report in order to define the "Dream Multidisciplinary Team for lung cancer". ${ }^{11}$ This 